\title{
TÍTULO V DE LA CONSTITUCIÓN DE CÁDIZ: PODER JUDICIAL, ORIGEN DEL TRIBUNAL SUPREMO, Y UNIDAD DE CÓDIGOS
}

PEDRO J. TENORIO SÁNCHEZ 


\section{SUMARIO}

1. PRINCIPIO DE DIVISIÓN DEL PODER Y SU PLASMACIÓN EN LA CONSTITUCIÓN DE CÁDIZ. 2. EL PODER JUDICIAL EN LA CONSTITUCIÓN DE CÁDIZ. 2.1. Características del Poder judicial en la Constitución de Cádiz. 2.2. Estructura del Poder judicial. 2.3. Tribunal Supremo. 3. OTROS CONTENIDOS DEL TÍTULO V: GARANTÍA JUDICIAL DE LA LIBERTAD PERSONAL, DERECHO A NO DECLARAR CONTRA SÍ MISMO, GARANTÍAS PROCESALES, DERECHO A LA INVIOLABILIDAD DEL DOMICILIO, GARANTÍA DE LA PROPIEDAD Y DERECHO EXCEPCIONAL. 3.1. Garantía judicial de la libertad personal. 3.2. Derecho a no declarar contra sí mismo. 3.3. Garantías procesales para el inculpado. 3.4. Garantía de la propiedad. 3.5. Derecho a la inviolabilidad del domicilio. 3.6. Humanización del tratamiento penitenciario. 3.7. Derecho excepcional. 3.8. Efectividad de las garantías. 4. UNIDAD DE CÓDIGOS. 


\title{
TÍTULO V DE LA CONSTITUCIÓN DE CÁDIZ: PODER JUDICIAL, ORIGEN DEL TRIBUNAL SUPREMO, Y UNIDAD DE CÓDIGOS*
}

\author{
POR \\ PEDRO J. TENORIO SÁNCHEZ \\ Catedrático de Derecho Constitucional \\ UNED \\ Ex Letrado del Tribunal Constitucional
}

\section{PRINCIPIO DE DIVISIÓN DEL PODER Y SU PLASMACIÓN EN LA CONSTITUCIÓN DE CÁDIZ}

Conforme al artículo 16 de la Declaración de Derechos del Hombre y del Ciudadano de 1789, toda sociedad en la que la garantía de los derechos no está asegurada la separación de los poderes establecida, no tiene Constitución. Es un punto pacífico del Derecho constitucional del Estado democrático liberal que el término Constitución en sentido estricto ha de reservarse a aquella que cumple este principio, a aquella que está informada por el principio de división del poder. Principio de división del poder que no tiene solamente un sentido racionalizador del ejercicio del poder, que no está orientado solamente a la eficacia del ejercicio del poder, sino que tiene un sentido garantista.

* El presente trabajo ha sido realizado en el marco del Proyecto de Investigación «La prehistoria del Derecho Constitucional» (DER 2009-11050), financiado por el Ministerio de Ciencia e Innovación. 
La teoría moderna de la separación de poderes (LOCKE, MONTESQUIEU) ha intentado hacer posible una antigua idea en términos jurídicos adecuándola al dogma de la soberanía estatal única e indivisible. En este sentido, la teoría moderna —que no contemporánea— constituye una de las respuestas históricas a un problema permanente de las organizaciones políticas.

La recepción en España de las ideas ilustradas tuvo lugar desde la segunda mitad del siglo XVIII ${ }^{1}$. Y en consecuencia esa línea de pensamiento se proyectó en la obra de quienes emprendieron los cambios políticos de los primeros años del siglo XIX.

Desde el día en que se reunieron las Cortes en la Isla de León el 24 septiembre 1810, a pesar de que tal reunión se hacía en cumplimiento de los deseos de FERNANDO VII y en ejecución de los propósitos de la Junta Central, como señaló SÁNCHEZ AGESTA, «las Cortes de Cádiz se afirmaron como un poder revolucionario y constituyente, depositario de la soberanía nacional $»^{2}$, con la aprobación del decreto presentado a la Cámara MUÑOZ TORRERO y leído por LUJÁN, que contenía los dos principios básicos que habrían de informar la Constitución: soberanía nacional y separación de poderes.

Ya algunos informes evacuados en respuesta a la consulta formulada por la Junta Central a través de la Comisión de Cortes son expresión del alto grado de penetración de las doctrinas de LOCKE y MONTESQUIEU ${ }^{3}$.

En efecto, en la construcción de la moderna visión del principio de división del poder es fundamental el pensamiento y la obra de LOCKE ${ }^{4}$ y de MONTES-

1 Entre otros, SÁnchez Agesta, L. (1953) El pensamiento político del despotismo ilustrado, Madrid.

2 SÁnchez Agesta, L. (1984). Historia del constitucionalismo español, Madrid, Editora nacional, página 54

3 Moreno Pastor, L. (1989). Los orígenes del Tribunal Supremo 1812-1838, Madrid, editado por el Ministerio de Justicia, págs. 39 y ss. Resulta curioso, entre los documentos reunidos mediante la Consulta al país, el del cura de Higuera de la Real, Miguel Agustín Jarillo, que en un extenso informe fechado al 10 septiembre 1809, consideraba necesario para asegurar la observancia de las leyes fundamentales del reino, erigir un tribunal «con el nombre de Constitucional, o ya sea Nacional, cuyo destino y cuya ocupación sea sola y únicamente velar sobre la más exacta observación de la constitución y leyes establecidas en las Cortes generales... El ideado Tribunal en nada debe depender del rey...».

${ }^{4}$ Locke, J. (1690) en su obra Segundo Tratado del Gobierno Civil (Madrid, Aguilar, 1986), se ocupa del problema de la división del poder. Para LOCKE, el poder legislativo es aquel que tiene el derecho de decidir cómo emplear la fuerza de la sociedad política para la conservación de la sociedad y de sus miembros. Dado que las leyes, cuya aplicación es constante y vigencia continua, requieren poco tiempo para ser creadas, no es necesario que el poder legislativo esté siempre actuando, ya que no tiene siempre un trabajo que realizar. Pero, dado que las leyes tienen una vigencia duradera y requieren una ejecución de observancia continuas es necesaria la existencia de un poder que esté siempre en funcionamiento; por eso se llega a menudo a separar el poder legislativo del poder ejecutivo. Además, la existencia de la comunidad implica el poder de guerra y de paz, de acordar ligas, alianzas y tratados con todas las personas y las comunidades extrañas a la sociedad política. 
QUIEU, que sería objeto de diferente aplicación en Europa que en Estados Unidos. En este último país, la ausencia de las cámaras legislativas de los Secretarios que auxilian al Presidente caracterizan al sistema como de separación de poderes, distinguiéndose de lo que predominará en Europa, donde los miembros del gobierno han de ser miembros de las Cámaras parlamentarias. Pero en ambas versiones, el poder judicial está separado de los otros dos.

Resulta curioso que tanto en el ámbito del Derecho constitucional como en la ciencia política se adopte como formulación de la división del poder la «separación de poderes» de MONTESQUIEU, ya sea para desmontarla, ya para ensalzarla.

En algunos casos, se ha señalado que es sorprendente que unos pocos párrafos dedicados a la constitución inglesa hayan tenido tanta repercusión en la historia jurídico política. Se ha señalado que estos párrafos de MONTESQUIEU descansaban en una interpretación errónea de la realidad de la constitución inglesa y que además se referían sólo a ella 5 .

Al respecto hay que señalar que una cosa es admitir que las afirmaciones respecto de la constitución inglesa se basaran en una contemplación errónea de la misma (o a lo mejor forzada) y otra distinta es admitir que la idea de la división del poder era accidental en el pensamiento de MONTESQUIEU. Como ha recordado TORRES DEL MORAL 6 , ya en Grandeza y decadencia de los romanos habla MONTESQUIEU del gobierno moderado, o sea aquél en el que no se abusa del poder. Y lo cifra principalmente, lo mismo que hará en El espíritu de las leyes, en la división del poder.

El referido principio va a quedar recogido ${ }^{7}$ con fórmula inspirada en los autores referidos y en la Constitución francesa de 1791, principalmente en los si-

Poder que se podría llamar, dice, federativo. El poder federativo, sin embargo se adapta menos que el ejecutivo para ser dirigido por leyes. Pero es difícil que el poder ejecutivo y el federativo estén separados. Por otro lado, concibe como poder supremo al legislativo.

Falta en LOCKE la referencia a la función jurisdiccional. Tal ausencia se explica por la singular experiencia inglesa. Las fuentes consuetudinarias del derecho inglés, y especialmente del Common law, el papel creativo del juez anglosajón, el hecho de que en el vértice de los tribunales se encontrara la Cámara de los lores, revela cómo en la experiencia inglesa la función jurisdiccional se encontraba en estrecha conexión orgánica y funcional con la función legislativa.

5 Cfr. Alzaga Villamil, Ó. (2011). «La Constitución de Cádiz y el Poder judicial», en EsCudero, J. A. (dir.), Cortes y Constitución de Cádiz. Doscientos años, Madrid, Espasa Libros, 2011, págs. 137 y ss., esp. pág. 140.

${ }^{6}$ En efecto, en su artículo «Ciencia y método en la obra de Montesquieu» publicado en la Revista de la Facultad de Derecho de la Universidad Complutense de Madrid, Vol. XVIII, núms. 50-51, 1978, págs. 403 y ss., señala TORRES DEL MORAL que ya en La grandeza de los romanos habla MONTESQUiEU del gobierno moderado, o sea aquél en el que no se abusa del poder.

7 Señala Alzaga Villaamil que con el Decreto de las Cortes de 24 de septiembre de 1810, 
guientes artículos: 15 («La potestad de hacer las leyes reside en las Cortes con el Rey», 16 («La potestad de hacer ejecutar las leyes reside en el Rey») y 17 («La potestad de aplicar las leyes en las causas civiles y criminales reside en los tribunales establecidos por la ley»).

Es en este último aspecto en el que debemos de centrarnos en el presente trabajo.

\section{EL PODER JUDICIAL EN LA CONSTITUCIÓN DE CÁDIZ}

\subsection{Características del Poder judicial en la Constitución de Cádiz}

El Título V tiene como rúbrica «De los Tribunales y de la Administración de Justicia en lo civil y en lo criminal» ${ }^{8}$. Ha escrito ALZAGA VILLAAMIL que en este Título la Constitución sienta no sólo las bases sino las paredes maestras y algo más de un auténtico poder judicial en nada menos que sesenta y seis artículos (del 242 al 308) ${ }^{9}$. Según ARTOLA ${ }^{10}$, la nueva organización de los tribunales enfrentó de modo radical a las Cortes con la totalidad del mecanismo central del Gobierno borbón, especialmente con el hasta entonces omnipotente Consejo de Castilla. La traslación de la competencia jurídica de los Consejos a un

que importó sin reservas la doctrina de la división de poderes, había importado no solamente las célebres tesis de MONTESQUiEU sino que, en realidad, significaba asumir las paredes maestras de la arquitectura constitucional británica. Alzaga VillaAmil, «La Constitución de Cádiz...,» op. cit., pág. 143.

${ }^{8}$ Durante la vigencia dela Constitución de 1837, un Decreto posterior al texto constitucional declaró subsistentes, por el momento, las disposiciones del Título V de la Constitución de 1812, relativo a la Administración de Justicia, en lo que no hubiesen sido derogadas por la nueva Constitución. V. Torres del Moral, Antonio, Constitucionalismo histórico español, Servicio de Publicaciones de la Facultad de Derecho de la Universidad Complutense, Madrid, 2004, pág. 69.

9 Alzaga Villaamil, La Constitución de Cádiz..., op. cit., pág. 147. El mismo autor en su trabajo El Poder judicial en las Constituciones españolas, cit., pág. 64, destaca entre las singularidades de la constitución doceañista las siguientes: la primera, que consagra a la cabeza de la Administración de Justicia un tribunal en la Corte (es decir, en Madrid), denominado Supremo Tribunal de Justicia, al que se reserva un tratamiento detallado...; la segunda, una innata desconfianza en los Jueces, apoyada en la alergia que hacia los mismos destilaba la Constitución francesa de 1791, y que en algún aspecto parece inspirada también en las reflexiones de MoNTESQUieu. V. también, SALGAdo SuÁreZ, F. (1981). «El Poder judicial en las Constituciones españolas», en Revista Jurídica de Asturias, enero-junio 1981, Academia Asturiana de Jurisprudencia, págs. 81 y ss.

10 Artola Gallego, M. (1988). La España de Fernando VII, Tomo XXVI, de la Historia de España, dirigida por Menéndez PIDAL, Espasa Calpe, Madrid, 1988, pág. 481. 
tribunal supremo anula por entero aquellos, al no dejarles campo alguno de intervención.

Entre nosotros, la Constitución de 1812, en aplicación de las teorías de MONTESQUIEU acerca de la división del poder, estableció la separación entre poder ejecutivo y poder judicial ${ }^{11}$.

Vamos a comprobar cómo en la Constitución de Cádiz estaban contenidos los principios cardinales esenciales de un Poder judicial propio de un Estado liberal.

En un Estado democrático liberal la jurisdicción es aquella función del Estado que consiste en resolver los litigios que ante ella plantean las partes mediante unos órganos especialmente instituidos para este fin juzgados y tribunales y un proceso con una serie de garantías ${ }^{12}$. Se distingue, por tanto, de la función ejecutiva, aun cuando ello no sea pacífico ni siquiera en la actualidad (piénsese en la escuela de Viena).

Pues bien, la Constitución de Cádiz, Título V, comienza un reconocimiento del principio de exclusividad judicial en varias de sus facetas: «la potestad de aplicar las leyes en las causas civiles y criminales pertenece exclusivamente a los Tribunales», dice el artículo 242.

Esto se completa con el envés, que aparece en el artículo 243 , formulando negativamente el principio: «ni las Cortes ni el Rey podrán ejercer en ningún caso las funciones judiciales».

Se complementa la configuración de este principio con la afirmación de que «los Tribunales no podrán ejercer otras funciones que las de juzgar y hacer que se ejecute lo juzgado» que es lo que dice el artículo 245 recogiendo la otra vertiente del principio de exclusividad jurisdiccional.

Esta nítida separación de funciones se justifica en el Discurso preliminar con base en la necesidad de que la potestad de aplicar las leyes a los casos particulares no se convierta en tiranía; concretamente se dice «se separan de tal modo las funciones de juez de cualquiera otro acto de la autoridad soberana, que nunca podrán ni las Cortes ni el Rey ejercerlas bajo ningún pretexto».

11 Pero no fue ésta la tónica dominante en el siglo XIX. Baste como muestra recordar que el propio texto — no ya la realidad extraconstitucional— de 1845 considera todavía la autoridad judicial como una desmembración del poder ejecutivo

12 En este sentido, nuestra Constitución de 1978 dice en el arte 117.3 que el ejercicio de la potestad jurisdiccional en todo tipo de procesos, juzgando y haciendo ejecutar lo juzgado, corresponde exclusivamente a los juzgados y tribunales determinados por las leyes. La función jurisdiccional comprende, pues, no sólo juzgar, sino hacer ejecutar lo juzgado. En el arte 117.4 establece que los juzgados y tribunales no ejercerán más funciones que las señaladas en el apartado anterior y las que expresamente les sean atribuidas por la ley de garantía de cualquier derecho. Así por ejemplo, junto a las funciones de tipo jurisdiccional, ejercen también las propias del Registro civil. 
No alcanzan a desdibujar esta separación ni el art. 257, conforme al cual la justicia se administra en nombre del Rey, ni el artículo $171.2^{\circ}$, conforme al cual al Rey le corresponde la facultad de «cuidar de que en todo el Reino se administre pronta y cumplidamente la justicia».

Aún en nuestros días, el principio de unidad jurisdiccional coexiste con la jurisdicción militar o el Tribunal de Cuentas. La existencia de estas últimas jurisdicciones no obsta para la vigencia de dicho principio de unidad, pues lo que éste exige es que toda función jurisdiccional sea ejercida por jueces y magistrados independientes, inamovibles, responsables, sometidos únicamente al imperio de la ley y que actúen mediante un proceso con todas las garantías. Históricamente, la unidad jurisdiccional ha sido una reivindicación de gran relevancia, pero su sentido era precisamente obtener juicios imparciales con todas las garantías, no se trata de sacrificar las ventajas que, por ejemplo, produce la especialización por razón de la materia ${ }^{13}$.

El artículo 248 («En los negocios comunes, civiles y criminales no habrá más que un solo fuero para toda clase de personas») recoge el principio de igualdad del fuero. Este va a tener dos salvedades: el fuero eclesiástico y el castrense (artículos 249 y 250 , respectivamente). En efecto, conforme al art. 249 «Los eclesiásticos continuarán gozando del fuero de su estado, en los términos que prescriben las leyes o que en adelante prescribieren». Y según el art. 250 «Los militares gozarán también de fuero particular, en los términos que previene la ordenanza o en adelante previniere».

A lo que debe añadirse que, conforme al art. 263, «Pertenecerá a las audiencias conocer (...) de las causas de suspensión y separación de los jueces inferiores de su territorio, en el modo que prevengan las leyes, dando cuenta al Rey».

También encontramos una previsión de posible creación por la ley de jurisdicciones especializadas en el art. 278: «Las leyes decidirán si ha de haber tribunales especiales para conocer de determinados negocios».

Aunque la Constitución no recoge expresamente el principio de independencia judicial ${ }^{14}$, la viene a establecer al constitucionalizar la garantía de in-

${ }^{13}$ Nuestra Constitución vigente reconoce que el principio de unidad jurisdiccional es básico en nuestra organización judicial artículo 117.5. Según el artículo 117.6 «se prohíben los tribunales de excepción». Por su parte, el art. 26 establece que «se prohíben los tribunales de honor en el ámbito de la administración civil y de las organizaciones profesionales». En esta línea, cabe mencionar también la prohibición de que la administración civil pueda imponer sanciones que consistan en privación de libertad (artículo 25.3). En definitiva, se trata de evitar que subsistan residuos de jurisdicciones corporativas o gremiales contrarias al monopolio estatal de la jurisdicción.

${ }^{14}$ En el mismo sentido, Muñoz de Bustillo Romero, C. (1989). Materiales para el estudio de la Constitución de Cádiz, Tecnos, Sevilla, 1989, págs. 545 y ss., esp. pág. 553. 
amovilidad judicial en el artículo 252: «Los magistrados y jueces no podrán ser depuestos de sus destinos, sean temporales o perpetuos, sino por causa legalmente probada y sentenciada; ni suspendidos, sino por acusación legalmente intentada». En realidad, dice ALZAGA VillaAmiL, la independencia no se establece solo por el art. 252, sino además por otras vías confluyentes: a) potestad exclusiva de los tribunales para entender de las causas civiles y militares (art. 242); b) prohibición de que ni las Cortes ni el Rey ejerzan funciones judiciales (art. 243); c) prohibición de que los tribunales ejerzan funciones extrajudiciales (art. 245); d) necesidad de que Jueces y Magistrados cumplan con las calidades determinadas por las leyes (art. 251); e) ausencia de prejuicios en los Magistrados, de manera de que los que hubieran fallado en la segunda instancia, no podían asistir a la vista del mismo pleito en la tercera (art. 264) ${ }^{15}$.

Se recoge el principio de responsabilidad judicial ${ }^{16}$ diciendo que «Toda falta de observancia de las leyes que arreglan el proceso en lo civil y en lo criminal, hace responsables personalmente a los jueces que la cometieren» (art. 254). Además, para prevenir la corrupción en la administración de justicia, el art. 255 establece que «El soborno, el cohecho y la prevaricación de los magistrados y jueces producen acción popular contra los que los cometan»y, por lo que se refiere al Tribunal Supremo y a sus miembros, el art. 261.5 establece: «Toca a este supremo tribunal: (...) Quinto. Conocer de todas las causas criminales que se promovieren contra los individuos de este supremo tribunal. Si llegare el caso en que sea necesario hacer efectiva la responsabilidad de este supremo tribunal, las Cortes, previa la formalidad establecida en el artículo 228, procederán a nombrar para este fin un tribunal compuesto de nueve jueces, que serán elegidos por suerte de un número doble».

Como precedente del sometimiento exclusivo al imperio de la ley ha de señalarse el art. 279, tan importante en el contexto bélico en que se aprueba la Constitución: «Los magistrados y jueces al tomar posesión de sus plazas jurarán guardar la Constitución, ser fieles al Rey, observar las leyes y administrar imparcialmente la justicia».

La idea de que la justicia se debe administrar con todas las garantías de alguna manera encuentra un antecedente en el art. 244: «Las leyes señalarán el orden y las formalidades del proceso, que serán uniformes en todos los tribunales; y ni las Cortes ni el Rey podrán dispensarlas».

15 Alzaga Villaamil, Ó., «La Constitución de Cádiz...,» págs. 153-154.

16 Según Garriga, C. y Lorente, M. (2007). la responsabilidad de los empleados públicos es el elemento clave y más característico, definitorio, del modelo constitucional gaditano, y por eso es el hilo conductor de todos los trabajos de su obra Cádiz, 1812. La Constitución jurisdiccional, Madrid, Centro de Estudios Políticos y Constitucionales, 2007, págs. 27 y ss. 
Más concretamente, el principio del juez natural o juez ordinario predeterminado por la ley aparece en el artículo 247: «Ningún español podrá ser juzgado en causas civiles ni criminales por ninguna comisión, sino por el tribunal competente determinado con anterioridad por la ley».

\subsection{Estructura del Poder judicial}

El Poder judicial del Estado democrático liberal tiene una singular estructura diversa de la que tiene la administración pública. Se compone de una multiplicidad de órganos cada uno de los cuales es depositario de toda la potestad jurisdiccional dentro de las atribuciones que tiene conferidas.

Esto lo ha expresado la doctrina italiana señalando que, a diferencia de otras funciones del Estado, la función jurisdiccional es difusa y no concentrada y que, precisamente por eso la jurisdicción rechaza, como íntimamente contradictoria con su esencia, la idea de órgano superior jerárquico. Cualquier juez o tribunal es titular de la función jurisdiccional de un modo directo e inmediato. Los órganos judiciales, en el ejercicio de la función jurisdiccional no están ligados por vínculos de coordinación y subordinación. Ni el poder ejecutivo ni el legislativo son difusos.

Dada esta naturaleza peculiar del Poder judicial, no puede sorprendernos que en la Constitución de 1812 se intentara establecer la base de la planta judicial en los arts. 271 a 275, a los que cabría añadir, aunque tengan además un sentido propio, los artículos dedicados al Tribunal Supremo: arts. 259 a 261.

La organización de la nueva planta de los tribunales de justicia se puede considerar como una de las principales reformas efectuadas por los Diputados gaditanos ${ }^{17}$. La Constitución, por su parte, estructura los tribunales conforme a los artículos 271 y siguientes en las siguientes instancias: alcaldes (según el artículo 275: «en todos los pueblos se establecerán alcaldes, y las leyes determinarán la extensión de sus facultades, así en lo contencioso como en lo económico»); juzgados (según el artículo 273: «se establecerán partidos proporcionalmente iguales, y en cada cabeza del partido habrá un juez de letras con un juzgado correspondiente»); audiencias (respecto de las cuales el artículo 271 establece que tanto el número de sus magistrados, que no podrá ser inferior a siete, como la forma de estos tribunales y el lugar de su residencia, se determinarán por leyes y reglamentos especiales) y el Tribunal Supremo de Justicia, del que nos habla el artículo 259 y respecto del cual las Cortes deberán determinar el

17 Muñoz de Bustillo Romero, op. cit., págs. 545 y ss. 
número de magistrados que habrán de componerlo y las salas en que habrá de distribuirse.

\section{Ausencia del jurado}

No se recoge la institución del jurado, que a lo largo del siglo XIX va a convertirse en uno de los elementos que van a dividir a progresistas y moderados (en concreto la atribución de los delitos de libertad de expresión a jurado).

Tan solo se dice en el art. 307 que «Si con el tiempo creyeren las Cortes que conviene haya distinción entre los jueces del hecho y del derecho, la establecerán en la forma que juzguen conducente»

El Discurso preliminar dice que es conveniente para el perfeccionamiento de la administración de justicia la separación de las funciones que ejercen los jueces en fallar a un mismo tiempo sobre el hecho y el derecho. Concretamente, dice «que no duda que algún día se establezca entre nosotros la saludable y liberal institución de que los españoles puedan terminar sus diferencias por jueces elegidos de entre sus iguales»; sin embargo, más adelante la Comisión reconocerá «la imposibilidad de plantear por ahora el método conocido con el nombre de juicio de jurados».

A todo ello se añade en el Discurso preliminar una serie de elogios a la institución en Inglaterra acompañada de la argumentación de la inconveniencia e inoportunidad de introducir los mismos en nuestro sistema: «su modo de enjuiciar es del todo diferente del que se usa entre nosotros, y hacer una revolución total en el punto más difícil, más trascendental y arriesgado de una legislación, no es obra que pueda emprenderse entre los apuros y agitaciones de una convulsión política»

\subsection{Tribunal Supremo}

Los orígenes del Tribunal Supremo se extienden desde el año 1812, año de creación del Tribunal por la Constitución de Cádiz (artículo 259) hasta 1838, en que el decreto del 4 noviembre lo configura como órgano de casación, asignándole por primera vez la competencia para pronunciarse sobre el fondo de los asuntos.

En muchos libros de Derecho procesal y algunos de Historia del Derecho, se afirma que el Tribunal Supremo de la Constitución de Cádiz fue la resultante del tipo de Estado que, alumbrado por la Revolución francesa, es consecuencia de la división de poderes y más concretamente de la supremacía de la ley, que tiene 
como consecuencia la anulabilidad de los actos de los jueces y tribunales que vulnerasen aquella, o la interpretación que de la misma hubiera venido dando la doctrina legal. Y es verdad que el Tribunal Supremo, como tribunal de casación, es una pieza esencial del Estado liberal, pero no fue en esos términos como fue alumbrado en la Constitución de Cádiz.

En efecto, MORENO PASTOR, en su obra sobre Los orígenes del Tribunal Supremo 1812-1838 ${ }^{18}$, ha mostrado que el nacimiento de nuestro Tribunal Supremo como pieza esencial del Estado liberal fue resultado de un proceso más largo y más complejo, en el que confluyen ideas de origen francés con instituciones autóctonas.

El Tribunal Supremo creado por la constitución de Cádiz tiene unas competencias considerablemente modestas ${ }^{19}$ y este rasgo se mantendrá durante el trie-

18 Moreno Pastor, L. (1989). Madrid, editado por el Ministerio de Justicia.

19 Art. 261: «Toca a este supremo tribunal:

Primero. Dirimir todas las competencias de las audiencias entre sí en todo el territorio español, y las de las audiencias con los tribunales especiales, que existan en la Península e Islas adyacentes. En Ultramar se dirimirán éstas últimas según lo determinaren las leyes.

Segundo. Juzgar a los secretarios de Estado y del Despacho, cuando las Cortes decretaren haber lugar a la formación de causa.

Tercero. Conocer de todas las causas de separación y suspensión de los consejeros de Estado y de los magistrados de las audiencias.

Cuarto. Conocer de las causas criminales de los secretarios de Estado y del Despacho, de los consejeros de Estado y de los magistrados de las audiencias, perteneciendo al jefe político más autorizado la instrucción del proceso para remitirlo a este tribunal.

Quinto. Conocer de todas las causas criminales que se promovieren contra los individuos de este supremo tribunal. Si llegare el caso en que sea necesario hacer efectiva la responsabilidad de este supremo tribunal, las Cortes, previa la formalidad establecida en el artículo 228, procederán a nombrar para este fin un tribunal compuesto de nueve jueces, que serán elegidos por suerte de un número doble.

Sexto. Conocer de la residencia de todo empleado público que esté sujeto a ella por disposición de las leyes.

Séptimo. Conocer de todos los asuntos contenciosos pertenecientes al real patronato.

Octavo. Conocer de los recursos de fuerza de todos los tribunales eclesiásticos superiores de la Corte.

Noveno. Conocer de los recursos de nulidad, que se interpongan contra las sentencias dadas en última instancia para el preciso efecto de reponer el proceso, devolviéndolo, y hacer efectiva la responsabilidad de que trata el artículo 254. Por lo relativo a Ultramar, de estos recursos se conocerá en las audiencias en la forma que se dirá en su lugar.

Décimo. Oír las dudas de los demás tribunales sobre la inteligencia de alguna ley, y consultar sobre ellas al Rey con los fundamentos que hubiere, para que promueva la conveniente declaración en las Cortes.

Undécimo. Examinar las listas de las causas civiles y criminales, que deben remitirle las au- 
nio liberal, por lo que no se le dará gran importancia doctrinalmente ${ }^{20}$. El análisis de las competencias enumeradas por el art. 261 muestra que la preocupación de los constituyentes al crear el Tribunal Supremo era dar respuesta a una cuestión fundamental: la responsabilidad de los empleados públicos, tanto de los Secretarios de Despacho como de los Magistrados de las Audiencias. Esto aparece claro con la mera lectura del texto en las competencias primera, segunda, tercera, cuarta, quinta, sexta, octava y undécima. Pero es que además, LORENTE SARINENA $^{21}$ ha analizado que lo mismo ocurre con las otras dos grandes competencias que parecen diferenciarse: el recurso de nulidad y las consultas. El recurso de nulidad fue concebido por las Cortes Constituyentes como un medio dirigido a proteger lo que consideraban una necesidad política de primer orden: el funcionamiento ordenado de la Administración de Justicia. Por lo que se refiere a las consultas, el art. 261.10 convertía al Tribunal Supremo en un oyente atento de las dudas de los diferentes Jueces y Tribunales. Oyente, porque debía recibir las consultas, y atento, porque estaba obligado a opinar sobre ellas antes de elevarlas a las Cortes. Los Jueces de primera instancia y las Audiencias hicieron caso omiso de la advertencia jerárquica contenida en el art. 261.10, privando al Tribunal tanto del conocimiento de sus dudas, como de su derecho y obligación a exponer la opinión que tuviera sobre ellas.

Sobre esta modesta base competencial, la doctrina y luego la legislación le irán atribuyendo otras facultades más importantes y decisivas. Son éstas las que lo convertirán en órgano de control y homogeneización de la interpretación de la ley que hacen los tribunales inferiores.

El principio constitucional que inspira la transformación no es sólo el de división del poder, sino el de igualdad ante la ley. Y la transformación no se produce curiosamente en virtud de una rutilante importación de una competencia del tribunal de casación francés. El cambio decisivo se produjo de forma difícil de advertir, en forma de una atribución tradicional. Concretamente, es una modificación del viejo recurso de nulidad, llevada a cabo por el decreto de 4 de no-

\footnotetext{
diencias para promover la pronta administración de justicia, pasar copia de ellas para el mismo efecto al Gobierno, y disponer su publicación por medio de la imprenta».

20 JOAQUín Francisco PACHeCO, en sus magistrales lecciones de derecho público, durante el curso 1844-1845, del Ateneo madrileño, no dedicó ni un solo comentario (Lecciones del derecho político constitucional, Madrid, 1845) (editado por Centro de Estudios Constitucionales, 1984) al Tribunal Supremo. Es muy escasa la bibliografía sobre el Tribunal Supremo en las Cortes de Cádiz. Hasta la investigación de Moreno solamente había cuatro trabajos.

${ }^{21}$ Lorente Sariñena, M. (1989). «División de poderes e interpretación de la ley», en Materiales para el estudio de la Constitución de Cádiz, Sevilla, Tecnos, 1989, págs. 401 y ss., esp. pág. 405.
} 
viembre de 1838, la que hizo del Tribunal Supremo un órgano encargado de lo que 17 años más tarde se llamaría el recurso de casación, que convertiría al Tribunal Supremo en el órgano adecuado para homogeneizar la interpretación de la ley, necesidad del Estado de Derecho.

La nulidad como recurso del Tribunal Supremo venía recogida en la Constitución de 1812, pero de forma tan vaga e imprecisa que no llegó a poder utilizarse. Hasta el extremo de que un decreto del 17 julio 1813 declaró que no había lugar al recurso de nulidad en las causas criminales a pesar de la generosidad con que se había recogido el mismo en la Constitución. El Reglamento Provisional para la Administración de Justicia de 1835 reconocía el principio de que le correspondía al Tribunal Supremo conocer de los recursos de nulidad que, según lo que estableciesen las leyes, se hubieran de interponer respecto de las sentencias de las audiencias. Pero tal reglamento era de naturaleza exclusivamente orgánica, por lo que no llegaba a regular el recurso.

Una vez promulgada la Constitución de 1837, en la legislatura de ese año y en la de 1838, las Cortes discutieron un proyecto de ley que introducía y regulaba el recurso de nulidad. Entre las decenas de intervenciones que el debate suscitó, MORENO destaca dos.

La de Bravo Murillo, en la sesión del 25 enero 1838, en la que distingue el viejo recurso de injusticia notoria con el nuevo recurso de nulidad, que considera equiparable al recurso de casación francés.

La de PACHECO, en la sesión del 28 enero del mismo año, para quien «el recurso de nulidad es una garantía que el Congreso ha creído necesario conceder, no solamente a los litigantes sino también a la sociedad. Explicaré esto, porque es importante para mi propósito. El recurso de nulidad presenta dos ventajas; la una es la reparación de la nulidad que se ha cometido; la otra, y más principal en mi concepto, es la formación de una jurisprudencia uniforme, que acabe la obra principiada en la Constitución cuando ha sancionado en uno de sus artículos que la legislación de la Monarquía sea uniforme también; porque en vano sería una misma legislación, si la jurisprudencia, que es la aplicación y el complemento de la legislación misma, pudiera en algunas provincias ser diferente de lo que fuera en otras» ${ }^{22}$.

Por otro lado, el Tribunal Supremo aparece con unas facultades correctoras y disciplinarias que se venían atribuyendo al Consejo de Estado respecto de los jueces, lo que lo convierte en este sentido en un antecedente del actual Consejo General del Poder Judicial ${ }^{23}$.

22 Moreno, op. cit., pág. 262

23 Del principio de separación de poderes se ha derivado como principio característico del estado liberal la necesidad de que los órganos investidos de la función jurisdiccional sean distintos de 
El Tribunal Supremo tenía, pues, unas funciones limitadas y modestas, básicamente constreñidas a la resolución de los conflictos jurisdiccionales y a los llamados juicios de residencia.

\section{OTROS CONTENIDOS DEL TÍTULO V: GARANTÍA JUDICIAL DE LA LIBERTAD PERSONAL, DERECHO A NO DECLARAR CONTRA SÍ MISMO, GARANTÍAS PROCESALES, DERECHO A LA INVIOLABILIDAD DEL DOMICILIO, GARANTÍA DE LA PROPIEDAD Y DERECHO EXCEPCIONAL}

Como es sabido, una de las aportaciones de la Ilustración es la humanización del Derecho penal y del penitenciario así como las garantías de la libertad personal. Este segundo aspecto se concreta en el Capítulo III del Título V «De la Administracion de Justicia en lo Criminal», donde aparecen entreveradas algunas otras garantías. Se recoge el principio de abolición del tormento, de los apremios y de la pena de confiscación de bienes (artículos 303 y siguientes).

\subsection{Garantía judicial de la libertad personal}

Hay, por una parte, una serie de preceptos que garantizan la libertad personal mediante intervención judicial. En este sentido, el art. 287 dispone que «ningún español podrá ser preso sin que preceda información sumaria del hecho, por el que merezca según la ley ser castigado con pena corporal, y asimismo un mandamiento del juez por escrito, que se le notificará en el acto mismo de la prisión». A lo que el art. 290 añade que «el arrestado, antes de ser puesto en pri-

los titulares de las decisiones políticas que constituyen el poder legislativo y el poder ejecutivo: la existencia, en definitiva, de jueces independientes del poder político. Posteriormente, la exigencia de respeto a la independencia se hace extensiva respecto de cualquier poder político, social o económico.

El sentido de la independencia es garantizarla a cada titular de la función. Ahora bien, se suele hablar de independencia orgánica con referencia a la ausencia de intromisión del gobierno en la organización y administración de los tribunales lo que es denominado autogobierno del poder judicial. La independencia funcional, por su parte es la esencia misma de la función jurisdiccional.

Si bien en tiempos pasados se entendió que la independencia del poder judicial del ejercicio sus funciones era compatible con la retención de la función de administración de la jurisdicción por parte del ministerio de justicia, sin embargo, después de la Segunda Guerra Mundial, los países europeos occidentales tienden a implantar un órgano de autogobierno de la magistratura y lo mismo hay que decir de los países del Este europeo con posterioridad a la caída del muro de Berlín en 1989.

Pero era pronto para esto en 1812. 
sión, será presentado al juez, siempre que no haya cosa que lo estorbe, para que le reciba declaración; mas si esto no pudiere verificarse, se le conducirá a la cárcel en calidad de detenido, y el juez le recibirá la declaración dentro de las veinticuatro horas». En fin, el art. 293 dispone que «si se resolviere que al arrestado se le ponga en la cárcel, o que permanezca en ella en calidad de preso, se proveerá auto motivado, y de él se entregará copia al alcaide, para que la inserte en el libro de presos, sin cuyo requisito no admitirá el alcaide a ningún preso en calidad de tal, bajo la más estrecha responsabilidad».

\subsection{Derecho a no declarar contra sí mismo}

El art. 291 recoge un precepto que es antecedente del que, en nuestra Constitución actualmente vigente, establece que nadie está obligado a declarar contra sí mismo ${ }^{24}$ : «la declaración del arrestado será sin juramento, que a nadie ha de tomarse en materias criminales sobre hecho propio».

\subsection{Garantías procesales para el inculpado}

Se establece un proceso con garantías propias de un Estado de Derecho. En este sentido, el art. 300 establece que «dentro de las veinticuatro horas se manifestará al tratado como reo la causa de su prisión, y el nombre de su acusador, si lo hubiere». Por su parte, el art. 301 dispone: «Al tomar la confesión al tratado como reo, se le leerán íntegramente todos los documentos y las declaraciones de los testigos, con los nombres de éstos; y si por ellos no los conociere, se le darán cuantas noticias pida para venir en conocimiento de quiénes son». En fin, de conformidad con el art. 302, «el proceso de allí en adelante será público en el modo y forma que determinen las leyes».

\subsection{Garantía de la propiedad}

También se recogen determinadas garantías de la propiedad en el Estado de Derecho. En este sentido, el art. 294 establece que «sólo se hará embargo de bienes cuando se proceda por delitos que lleven consigo responsabilidad pecuniaria, y en proporción a la cantidad a que ésta pueda extenderse». Es de destacar también que el art. 304 dispone que «tampoco se impondrá la pena de confiscación de bienes».

${ }^{24}$ Art. 24.2, inciso primero CE. 


\subsection{Derecho a la inviolabilidad del domicilio}

El art. 306 es un antecedente del reconocimiento de la inviolabilidad del domicilio $^{25}$ : «no podrá ser allanada la casa de ningún español, sino en los casos que determine la ley para el buen orden y seguridad del Estado».

\subsection{Humanización del tratamiento penitenciario}

En otros preceptos se plasma la reforma del tratamiento del preso, haciéndolo más humano. En este sentido, el art. 297 dice que «se dispondrán las cárceles de manera que sirvan para asegurar y no para molestar a los presos: así el alcaide tendrá a éstos en buena custodia y separados los que el juez mande tener sin comunicación; pero nunca en calabozos subterráneos ni malsanos». Por su parte, los arts. 298 y 299 también operan en el mismo sentido. Según el art. 298, «la ley determinará la frecuencia con que ha de hacerse la visita de cárceles, y no habrá preso alguno que deje de presentarse a ella bajo ningún pretexto». Además, conforme al art. 299, «el juez y el alcaide que faltaren a lo dispuesto en los artículos precedentes, serán castigados como reos de detención arbitraria, la que será comprendida como delito en el código criminal».

Es muy destacable el art. 303, que establece que «no se usará nunca del tormento ni de los apremios».

Finalmente, según el art. 305, «ninguna pena que se imponga, por cualquier delito que sea, ha de ser trascendental por término ninguno a la familia del que la sufre, sino que tendrá todo su efecto precisamente sobre el que la mereció».

\subsection{Derecho excepcional}

Es propio del concepto racional normativo de constitución intentar regular incluso las situaciones excepcionales en la vida del Estado, aquellas en las que no pueden regir sus normas ordinarias ${ }^{26}$. En este sentido, el Capítulo III, que ha reconocido una variedad de derechos a los que hemos hecho referencia, se cierra con una previsión que podemos calificar de Derecho excepcional: el art. 308, según el cual «si en circunstancias extraordinarias la seguridad del Estado exigiese, en toda la Monarquía o en parte de ella, la suspensión de algunas de las formalidades prescritas en este capítulo para el arresto de los delincuentes, podrán las Cortes decretarla por un tiempo determinado».

${ }^{25}$ Art. 18.2 CE.

${ }^{26}$ En nuestra Constitución el Derecho excepcional está contenido en el art. 116 CE. 


\subsection{Efectividad de las garantías}

Las Cortes de Cádiz intentaron acabar con la confusión de competencias y la irresponsabilidad de los miembros del Poder Judicial, pero no puede olvidarse que la normativa creada por las referidas Cortes debía ser aplicada por un aparato judicial procedente del Antiguo Régimen. La consecuencia fue que los ciudadanos que se sintieron desprotegidos al ver inaplicadas las garantías procesales contenidas en la Constitución se dirigieron a las Cortes. Los pueblos, insatisfechos con la interpretación que hacían las Audiencias, recurrieron también a las Cortes, etc., por lo que las reclamaciones desbordaron al cuerpo legislativo ${ }^{27}$.

\section{UNIDAD DE CÓDIGOS}

\subsection{Principio de unidad}

En la sesión del día 21 de noviembre de 1811, se discutió, se votó y se aprobó el art. 257 del Proyecto de Constitución, que de esa manera, se convirtió en el art. 258 del texto constitucional, que recoge principio de unidad de códigos: «El Código civil y criminal y el de comercio serán unos mismos para toda la Monarquía, sin perjuicio de las variaciones, que por particulares circunstancias podrán hacer las Cortes».

La idea de unidad impregna todo el texto, como ha señalado entre nosotros OLIVENCIA $^{28}$. La Constitución es una, como uno es Dios, en cuyo nombre se dicta; una la Nación española ( «la reunión de todos los Españoles de ambos hemisferios», art. 1). El Reino de las Españas es uno e indivisible (art. 174); una, la soberanía «que reside esencialmente en la Nación» (art. 3); una, la Patria, a la que «todos los Españoles» tienen la «obligación de amar y de defenderla con las armas» (arts. 6 y 9).

La unidad inspira los conceptos esenciales, por encima de la enorme extensión y de la pluralidad de los territorios. Se impone en «ambos hemisferios» (arts. 1, $18,28)$ y en todos «los dominios de las Españas» (arts. 1, 5, 174). Una es la Nación, la Patria, la Monarquía, la Religión (art. 12: «única verdadera»); la representación nacional (art. 28); la cámara legislativa (art. 131) ${ }^{29}$.

En consecuencia, uno es el Consejo de Estado (art. 131); uno, el Tribunal Supremo de Justicia (art. 249); una, la Tesorería General (art. 345); una, la Contaduría mayor (art. 350); una, la fuerza militar nacional (art. 356); y, uno y «uni-

27 LORENTE SARIÑENA, op. cit., págs. 419 y 420.

28 Olivencia Ruiz, M. (2011) «Constitución y codificación», en Escudero, J. A. (dir.), Cortes y Constitución de Cádiz. Doscientos años, Madrid, Espasa Libros, págs. 164 y ss.

29 Olivencia, op. cit., pág. 165. 
forme», el plan general de enseñanza, la dirección general de estudios y la inspección de la enseñanza pública a su cargo (art. 369) ${ }^{30}$.

En este contexto se inscribe la unidad de códigos.

Ha de tenerse en cuenta que el panorama jurídico con el que se encontraban los constituyentes era caótico, por más que se hubiera intentado paliar con las recopilaciones, que eran colecciones de leyes y otras fuentes de normas escritas, agrupadas, agregadas una tras otra, pero no reconducidas a unidad sistemática. La Novísima Recopilación era de 15 de julio de 1805.

Nuestros Diputados gaditanos sin duda conocían los códigos franceses, pues el civil era de 1804 y el de comercio, de $1807^{31}$.

Aunque la aspiración codificadora no aparece sólo en la Constitución del 12, sino que va a ser una constante en las distintas constituciones (art. 4 de la Constitución de 1837; art. 4 de la de 1845; art. 5 de la de 1856; art. 91 de la 1869; art. 65 de la 1876), habrá que esperar a 1829 para el primer código de comercio, a 1885 para el segundo código de comercio y a 1889 para el primer código civil.

\subsection{Cataluña}

En su trabajo, titulado «Uniformismo jurídico y reacción en Cataluña», FERNÁNDEZ VILADRICH ${ }^{32}$ se propone destacar la forma en que los Diputados de Cortes por Cataluña, con sus reflexiones jurídicas, formuladas a lo largo de las sesiones parlamentarias, alentando la pervivencia del Derecho propio de la tierra catalana, pudieron tal vez contribuir a introducir, en la redacción del art. 258 de la Constitución, la cláusula «sin perjuicio de las variaciones». También intenta mostrar la validez efectiva que tuvo en el Derecho catalán el referido precepto constitucional.

Distingue el referido autor tres momentos en esta problemática.

Primero, se refiere a la consideración del alcance de la reforma legislativa anterior a la promulgación del art. 258 de la Constitución gaditana. El principal documento en que se basa es uno fechado el 13 de agosto de 1810 en Tarragona, cuando ya las Cortes se hallaban convocadas, por el que la Junta Superior del Principado de Cataluña, daba unas instrucciones a los Diputados catalanes ${ }^{33}$.

30 Olivencia, op. cit., pág. 166.

31 OlivenCia, op. cit., pág. 168.

32 Fernández Viladrich, J. (2011) «Uniformismo jurídico y reacción en Cataluña», en EscUDero, J. A. (dir.), Cortes y Constitución de Cádiz. Doscientos años, Espasa Libros, 2011, págs. 176 y ss.

33 En el referido documento, se puede leer «que aunque desde luego deben reconocerse las ventajas políticas que resultarían de uniformar la legislación y los derechos de todas las Provincias de la 
Cuando el autor referido resume la intervención de LÁZARO DE DOU en esta primera fase, señala que no sería imaginable que Cataluña apoyara la reforma de la legislación prescindiendo de su Derecho ${ }^{34}$.

En cuanto a la segunda fase, la aprobación del art. 258, frente a otros Diputados que hablaron en contra de las posibles excepciones a la unidad de códigos, señala FERNÁNDEZ VILADRICH ${ }^{35}$ que los Diputados catalanes guardaron silencio, lo que interpreta en el sentido de que vieron con buenos ojos la indeterminación de la fórmula propuesta, pues era lo más apropiado para que el pueblo catalán pudiera conservar su Derecho, de manera especial en la esfera de las leyes privadas.

En cuanto a la tercera fase, dice el referido autor ${ }^{36}$ que tras la aprobación de la Constitución, el movimiento codificador permaneció en vía muerta. Tan sólo nos han llegado fragmentos de un borrador de código mercantil en el que se conservan instituciones del Derecho marítimo catalán.

\subsection{Territorios vascos}

Tras la aprobación de la Constitución, las Cortes Generales y Extraordinarias, reunidas en Cádiz, ordenaron su publicación y juramento en los distintos territorios de España. Dicha orden llegó naturalmente a los territorios vascos, cada uno de los cuales responderá de forma tardía (a consecuencia de la guerra) y de modo particular ${ }^{37}$.

En Álava, la Constitución fue recibida sin reservas. Concretamente, fue presentada el 27 de noviembre de 1812, estando reunida la Provincia, en sus Juntas Generales Ordinarias. El día 27, la Constitución se publicó y se juró en los tér-

\footnotetext{
Monarquía para que no quede ésta después de la actual crisis hecha un cuerpo compuesto de partes heterogéneas; con todo, cuando no pensase así la pluralidad, o cuando insuperables obstáculos se opusiesen a la realización de esta medida saludable, en tal caso debe Cataluña no sólo conservar sus privilegios y fueros actuales, sino también los que disfrutó en el tiempo en que ocupó el Trono español la augusta casa de Austria. Dado que los incalculables sacrificios que en defensa de la Nación está haciendo Cataluña, la constituyen bien digna de recobrar sus prerrogativas; y tan extraordinarios esfuerzos de fidelidad y amor a su Soberano, han de ser poderosos para borrar de la estimación y aprecio hasta la menor sombra de pasados acontecimientos» (FERNÁNDEZ VILADRICH, op. cit., pág. 178).

34 FERNÁNDEZ Viladrich, op. cit., pág. 182.

35 FernándeZ Viladrich, op. cit., pág. 184.

36 FERnÁndeZ Viladrich, op. cit., págs. 187 y 188.

37 Sobre el tema, seguimos a Ayerbe IrIBAR; M. R. (2011). «Uniformismo jurídico y reacción en el País Vasco», en ESCUDERO, J. A. (dir.), Cortes y Constitución de Cádiz. Doscientos años, Espasa Libros, Madrid, págs. 191 y ss.
} 
minos y circunstancias en que se había solicitado, con la más plausible aclamación, regocijo y vivas ${ }^{38}$.

En Guipúzcoa, la adhesión a la Constitución y su juramento se realizó en las Juntas Generales de Deva, de 1813. Es verdad que se juró la Constitución, pero también que se encargó a la Diputación que iba suceder a las Juntas el tratar con el Gobierno la adecuación de la norma a la realidad guipuzcoana, muy distinta al resto de la Nación española, y perfectamente regulada por su propia constitución o código originario, que bien pudiera servir de modelo a nuevas normas de las Cortes. La Regencia reaccionó encomendando al jefe político de la Provincia que la Constitución se jurara en todos los pueblos, por todos los vecinos y el clero reunidos. Y existe constancia de que así se hizo en muchos de ellos ${ }^{39}$. El 17 de septiembre el jefe político de la Provincia remitió a la Regencia del Reino los testimonios de la publicación y juramento de los pueblos, pidiendo que se elevase noticia a las Cortes ${ }^{40}$.

En Vizcaya, se produjeron una serie de desórdenes a lo largo de los últimos meses, en 1812, y primeros de 1813, al enfrentarse los partidarios de la Constitución con los defensores del fuero ${ }^{41}$. En las actas de la Junta queda constancia de la lectura y acatamiento de la Constitución, pero existen documentos escritos que demuestran que la cuestión fue muy discutida ${ }^{42}$.

\subsection{Navarra}

Navarra ${ }^{43}$ era el único territorio de la Monarquía española que, al iniciarse el siglo XIX, conservaba la condición de reino. Por ello, el nuevo régimen constitucional entra en colisión con el estatus tradicional de este territorio. Habrá una corriente de pensamiento defensora de ese régimen privativo que, a partir de 1833, se plasmará en el carlismo, pero que es anterior. Los liberales también serán foralistas, es decir, defenderán junto con la Constitución un régimen privativo de Navarra, reducido a aspectos económico-administrativos, que será la solución institucional que se impondrá.

38 Ayerbe Iribar; M. R., op. cit., pág. 192.

39 Ayerbe Iribar; M. R., op. cit., pág. 198.

40 Ayerbe Iribar; M. R., op. cit., pág. 199.

41 Ayerbe Iribar; M. R., op. cit., pág. 202.

42 Ayerbe Iribar; M. R., op. cit., pág. 205.

43 GalÁn LORdA, M., «Uniformismo jurídico y reacción en Navarra», en Escudero, J. A. (dir.), Cortes y Constitución de Cádiz. Doscientos años, Espasa Libros, Madrid, 2011, págs. 115 y ss. 
En cada período de vigencia de la Constitución española de 1812 se instaura el régimen liberal en Navarra, con el cese consiguiente de las instituciones tradicionales y el establecimiento de unas nuevas instituciones constitucionales que dan lugar a la división de la opinión en dos corrientes: el defensor del tradicional régimen navarro junto con las instituciones propias del Antiguo Régimen, y el partidario del nuevo constitucionalismo. Así pues, cuando se aprobó la Constitución de Cádiz, las instituciones navarras salieron en defensa de la constitución histórica de Navarra, aunque ante la guerra se vieron obligadas a salir de Pamplona o suspender sus funciones. La institución más representativa en este período ${ }^{44}$ será la Diputación del Reino, transformada en Diputación provincial cada vez que se establezca el sistema constitucional. Liberada Pamplona en octubre de 1813, se proclamó la Constitución de Cádiz en un acto solemne protagonizado por el Ayuntamiento de la ciudad y la Diputación a pesar de que todavía casi la mitad del territorio navarro estaba ocupado por los franceses ${ }^{45}$. Hay que señalar que el Discurso Preliminar de la Constitución gaditana hace referencia a Navarra y, particularmente, al hecho de que su constitución sigue «viva y en ejercicio» ${ }^{46}$.

\section{RESUMEN}

El presente trabajo estudia el Título V de la Constitución de Cádiz de 1812, regulador del Poder Judicial, de algunos derechos fundamentales y del principio de unidad de códigos. Tiene una introducción sobre la doctrina de la división del poder en Locke y MONTESQUieu. El Poder Judicial en la Constitución de Cádiz tuvo gran importancia porque fue el que enfrentó a las Cortes con los antiguos Consejos de la Administración borbónica.

El trabajo comienza analizando la plasmación en la Constitución del principio de división de poderes. La recepción de este principio se hace bajo la influencia de MONTESQUiEU y de la Constitución francesa de 1791. No obstante, en el Discurso Preliminar con el que los constituyentes explicaban la Constitución, presentan a ésta como una recuperación de antiguas leyes de la Monarquía Hispánica.

44 GALÁn LORDA, op. cit., pág. 219.

45 GALÁn LORDA, op. cit., pág. 222.

46 Frente a la mayoritaria reacción contra la Constitución de 1812 en su primer período de vigencia y la aceptación de su derogación incluso por la Diputación provincial, que se había constituido a su amparo, en 1820 parece aceptarse con mayor naturalidad el nuevo régimen constitucional. Seguramente, fue determinante el hecho de que el Rey jurase la Constitución, ya que en todo caso, las instituciones navarras trataron de actuar conforme al poder legítimamente instituido. El sistema constitucional se implantará en Navarra con solidez a partir de 1836. V., en este sentido, GALÁN LORDA, op. cit., pág. 228. 
Por lo que se refiere a las características del Poder judicial, la Constitución sienta las bases y las paredes maestras del mismo. En particular, aunque no reconocen explícitamente la independencia judicial, la garantiza a lo largo de varios de sus preceptos. En la estructura judicial se sitúa en la base a los Alcaldes, y en el vértice, al Tribunal Supremo. Es de destacar que no se recoge la figura del jurado.

Por lo que se refiere al Tribunal Supremo, hay que señalar que no es la institución típica de un Estado de Derecho liberal. No lo llegará a ser hasta 1838, cuando se regule el recurso de nulidad, convirtiéndolo en una especie de recurso de casación.

El Título V contiene, por otra parte, una serie variada de garantías de la libertad personal, procesales, de la propiedad, del domicilio, y humaniza el tratamiento penitenciario. Una característica del mismo que hay que destacar es que recoge la propia posibilidad de que esos derechos y garantías sean suspendidos.

La Constitución recoge en el Título V, art. 258, el principio de unidad de códigos. Toda la Constitución está inspirada por la idea de unidad, pero, a la hora de formular la unidad de códigos, se prevé la posibilidad de que las Cortes hagan variaciones por particulares circunstancias. A pesar de ello, este principio tuvo alguna dificultad para ser aceptado en algunas regiones. Por lo que se refiere a Cataluña, el silencio de los Diputados catalanes en el debate del referido precepto, se ha interpretado en el sentido de que veían suficientemente garantizadas sus peculiaridades, no en el sentido de que renunciaran a ellas. Existen diferencias en la forma en que fue recibida la Constitución en cada una de las provincias del País Vasco. La recepción fue fácil en Álava, pero se hizo con reservas en Guipúzcoa, y dio lugar a serios enfrentamientos en Vizcaya. Navarra también opuso alguna resistencia a que desapareciera lo que consideraba la Constitución de su Reino. Aquí surgirá una corriente de pensamiento defensora del régimen privativo navarro que, a partir de 1833 , se plasmará en el carlismo.

Title:

TITLE V OF THE CONSTITUTION OF CÁDIZ: THE JUDICIARY, THE SUPREME COURT HOME AND UNIT CODES

\section{Summary:}

1. PRINCIPLE OF DIVISION OF POWER AND ITS EMBODIMENT IN THE CONSTITUTION OF CADIZ. 2. THE JUDICIARY IN THE CONSTITUTION OF CADIZ. 2.1. Features of the 
judiciary in the Constitution of Cadiz. 2.2. Structure of the Judiciary. 2.3. Supreme Court. 3. OTHER CONTENTS OF THE TITLE V: LEGAL GUARANTEE OF PERSONAL LIBERTY, THE RIGHT NOT TO INCRIMINATE ONESELF, DUE PROCESS, RIGHT TO THE INVIOLABILITY OF THE HOME, PROPERTY AND EXCEPTIONAL LAW. 3.1. Legal guarantee of personal freedom. 3.2. Right not to testify against himself. 3.3. Procedural safeguards for the accused. 3.4. Guarantee of property. 3.5. Inviolability of the home. 3.6. Humanization of prison treatment. 3.7. exceptional law. 3.8. Effectiveness of the assurances. 4. Unit codes.

\section{Abstract}

This article studies the Title V of the Constitution of Cadiz of 1812, regulating the judiciary, certain fundamental rights and the principle of unity of codes. It presents an introduction to the doctrine of separation of powers by LOCKE and MONTESQUIEU. The judiciary in the Constitution of Cadiz was very important because it brought into conflict the Courts and the old Bourbon Administration Councils.

The article begins by analyzing the translation of the constitutional principle of separation of powers. The reception of this principle was influenced by MonTESQUieu and the French Constitution of 1791. However, the Preliminary Discourse, which explains the Constitution, presented itself as a recovery of ancient laws of the Spanish Monarchy.

With regard to the characteristics of the judiciary, the Constitution provides its basis and guidelines. It recognizes the independence of the judiciary throughout some of its precepts, although not explicitly. The judicial structure places the mayors at the bottom, and the Supreme Court at the top. It is worth noticing that the jury is not among its provisions.

In relation to the Supreme Court, it should be noted that this institution is not a typical one for a liberal system, at least until 1838, when the nullity remedy is regulated and introduced as a tool of appeal.

Title $\mathrm{V}$ contains, on the other hand, a diverse series of guarantees on personal liberty, due process, property, and privacy. It also humanizes the treatment of prisoners. The possibility of suspension of such rights and guarantees is also provided.

In the Title V, Art. 258, the Constitution holds the principle of unity of codes. The entire Constitution is inspired by the idea of unity, but, while proclaiming the unity of codes, it foresees the possibility that the courts contemplate exceptions to particular circumstances. However, this principle had some difficulty in being accepted in some regions. 
In regard to Catalonia, the silence held by the Catalan members of the parliament in the debate of that precept has been interpreted as the following: their peculiarities were adequately guaranteed. They have not been interpreted as: they will give up these peculiarities. There are differences in the way the Constitution was received in each of the provinces of the Basque Country. The reception was easy in Álava, but accepted with certain reservations in Guipuzcoa. It led to a great controversy and conflicts in Vizcaya. Navarre also was reluctant to the disappearance of what it considered to be the Constitution of its own Kingdom. This way of thinking will give way to a particular Navarre system that, from 1833, will be represented and defended by the Carlists.

\section{Palabras clave}

división del poder - poder judicial - Tribunal Supremo - garantías procesales para el inculpado - unidad de códigos.

\section{Key words}

division of power - the judiciary - Supreme Court - procedural safeguards for the accused - unit codes. 
